\title{
Rotablation of a tricky calcified lesion in a tortuous right coronary artery
}

\author{
L. Rijk (D) · S. Hoseyni Guyomi · J. J. Remmen · A. J. M. Oude Ophuis
}

Published online: 17 January 2020

(c) The Author(s) 2020

\section{Answer}

During initial angiography severely calcified lesions were observed (Fig. la) for which we scheduled a rotablation procedure. The set-up for this procedure included a venous sheath with access through the right femoral vein with pacemaker lead which can be seen in Fig. $1 b$.

Immediately after rotablation a perforation occurred in a mid-segment of the right coronary artery. The Rotawire was replaced by a support wire and the resulting occlusion was crossed, followed by placement of a $3.0 \mathrm{~mm}$ covered stent through a Guidezilla catheter.

Under echocardiographic guidance a pigtail catheter was inserted for pericardial drainage. The pigtail was flushed with contrast fluid to secure position of the drain. Contrast fluid showed to be contained within the pericardial cavity, indicating a correct drain position (Fig. 1b). The pericardial drain was left in situ after complete drainage, therefore the risk of occlusion of the drain was negligible. Furthermore, because of the position of the aortic valve and its connection with the pericardial cavity, aortic valve cusps can be seen (Fig. 1b).

The patient was treated with fluid resuscitation and inotropic support. The total pericardial drainage was $200 \mathrm{cc}$ and the patient remained haemodynamically stable throughout the entire procedure. The proce- dure was continued through noncompliant balloon dilatation over the entire course of the vessel, followed by deployment of the 2.5 and $2.25 \mathrm{~mm}$ drugeluting stent distally. Finally, a $3.5 \mathrm{~mm}$ covered stent was placed in the mid-segment.

Post deployment angiography revealed a covered perforation with thrombolysis in myocardial infarction (TIMI) 3 flow. Our patient was discharged in good clinical condition after 3 days of hospitalisation.

Conflict of interest No benefits in any form have been received or will be received related directly or indirectly to the subject of this article. L. Rijk, S. Hoseyni Guyomi, J.J. Remmen and A.J.M. OudeOphuis certify that they have no commercial associations (e.g. consultancies, stock ownership, equity interest, patent/licensing arrangements, etc.) that might pose a conflict of interest in connection with the submitted article.

Open Access This article is licensed under a Creative Commons Attribution 4.0 International License, which permits use, sharing, adaptation, distribution and reproduction in any medium or format, as long as you give appropriate credit to the original author(s) and the source, provide a link to the Creative Commons licence, and indicate if changes were made. The images or other third party material in this article are included in the article's Creative Commons licence, unless indicated otherwise in a credit line to the material. If material is not included in the article's Creative Commons licence and your intended use is not permitted by statutory regulation or exceeds the permitted use, you will need to obtain permission directly from the copyright holder. To view a copy of this licence, visit http://creativecommons.org/licenses/by/4.0/.

\footnotetext{
L. Rijk $(\bowtie) \cdot$ S. Hoseyni Guyomi · J. J. Remmen · A. J. M. Oude Ophuis

Department of Cardiology, Canisius-Wilhelmina Ziekenhuis, Nijmegen, The Netherlands

rijk.leon@gmail.com
} 
Fig. 1 a Tortuous and calcified right coronary artery; b Angiographic image after rotablation

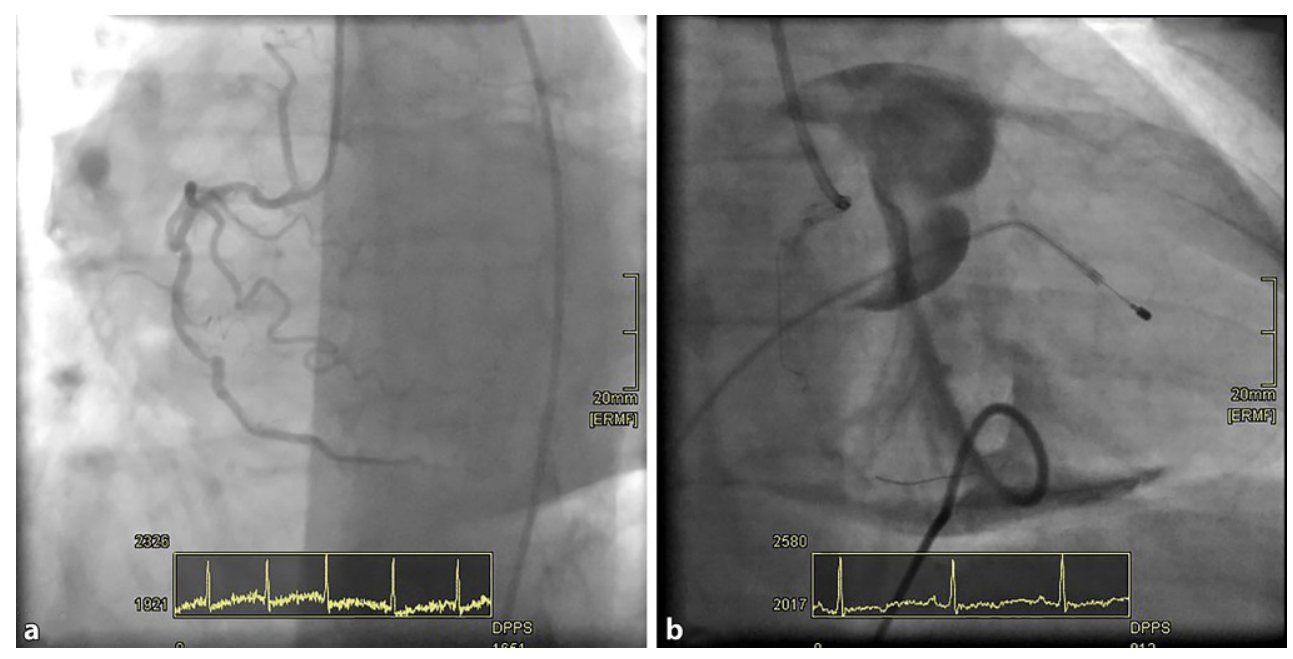

